\title{
Kerosene Oil Pneumonitis
}

\author{
Ranjan Kumar Singh \\ Consultant Physician, Anti-retroviral therapy Centre, District Hospital, Khagaria, Bihar, India.
}

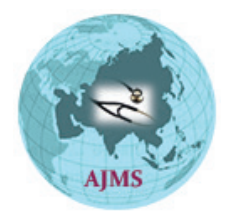

\section{A B S T R A C T}

Radiographic abnormalities in the lungs are very common in individuals positive for HIV antibody. Majority of lesions are of infective or neoplastic in origin. We present a case of chemical pneumonitis following regurgitation of kerosene oil in a patient positive for human immunodeficiency virus (HIV) antibodies. Chemical pneumonitis is diagnosed with a characteristic clinical history of regurgitation of fluid and gravity-dependent infiltration in the lung on chest $\mathrm{x}$-ray. Another condition arising from the aspiration of the fluid/chemical is negative-pressure pulmonary oedema which results from laryngeal spasm following regurgitation of fluid. Chest radiography, however, distinguishes it from chemical pneumonitis. Bilateral infiltration is seen in the former, while lesion at dependent portion of right lung is seen in the latter condition.

Key words: Chemical pneumonitis; Kerosene oil; HIV

Access this article online

\section{Website:}

http://nepjol.info/index.php/AJMS

DOI: 10.3126/ajms.v12i6.36847

E-ISSN: 2091-0576

P-ISSN: 2467-9100

Copyright (c) 2021 Asian Journal of Medical Sciences

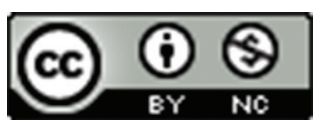

This work is licensed under a Creative Commons Attribution-NonCommercial 4.0 International License.

\section{INTRODUCTION}

Radiographic lesions in the lungs are very common in individuals positive for Human Immunodeficiency Virus (HIV) antibody. Majority of lesions are of infective in origin or due to malignant conditions -for example, bacterial infections, tuberculous and no-tuberculous mycobacterium, Pneumocystis Jirovecii, cryptococcal infections, Kaposi sarcoma, etc. Albeit, non-infective lesion such as chemical pneumonitis happens as a result of exposure of substances toxic to the lungs. It was first described by Curtis Lester Mendelson in the year 1946, in relation to gastric fluid aspiration during obstetric anaesthesia. ${ }^{1}$ Other causes of chemical pneumonitis include volatile hydrocarbons, i.e. diesel, petrol, kerosene oil (fire-eater's pneumonia) and mineral oil (lipoid pneumonia). ${ }^{2}$ Kerosene oil, also known as paraffin oil or home-heating oil in the United Kingdom, is a mixture of chemicals produced from the distillation of crude oil. ${ }^{3}$ Kerosene oil is still in use for ignition and illumination in the countryside of developing countries. Aspiration of a small amount of kerosene oil i.e. $0.2 \mathrm{ml}$ can cause pneumonitis.

\section{CASE PRESENTATION}

A 41-year-old male patient had pain over right side of chest and a cough with mucoid expectoration, of threeday duration. Expectorations had peculiar smell. He was positive for HIV antibody and was taking anti-retroviral drugs (tenofovir, lamivudine and efavirenz) for the past 5 years. His CD4+ T cell count was $549 / \mu \mathrm{l}$ at the time of presentation. Although the patient did not show sign of cyanosis; crackles were present at the right lung base on auscultation. The patient's erythrocyte sedimentation rate (ESR) was $24 \mathrm{~mm}$ in the first hour. Chest $\mathrm{x}$-ray obtained shortly thereafter (Figure 1A) showed consolidation in the lower zone of the right lung. Sputum microscopy and a nucleic acid amplification test for Mycobacterium tuberculosis were negative. Sputum culture for aerobes and anaerobes was also unremarkable. Of note, the patient had a history of regurgitation of kerosene oil (hydrocarbons) three days earlier, when he took kerosene oil full mouth for a few minutes as a home remedy for toothache. Thereafter he had pain over chest. Kerosene 
oil exposure, consolidation of the dependent part of the lung on chest $x$-ray and exclusion of bacterial infection led the diagnosis of chemical pneumonitis. The patient was prescribed bronchodilator and anti-inflammatory drugs. He recovered from chest pain and cough within two weeks. A chest x-ray (Figure 1B) obtained after two weeks showed resolution of the consolidation.

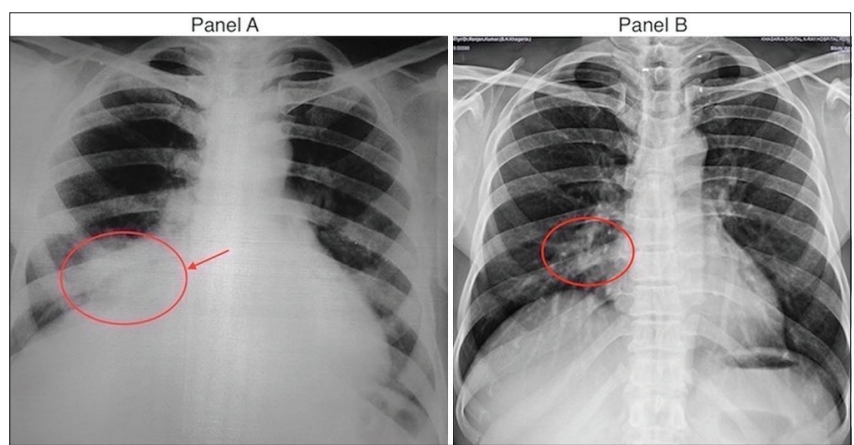

Figure 1: Chest radiograph (Panel A) shows consolidation in lower zone of right lung; Chest radiograph (Panel $B$ ) shows resolution of consolidation.

\section{DISCUSSION}

The CD4+ T cell counts in patients positive for HIV antibody predict possible differentials of pulmonary lesions. Tuberculosis and bacterial pneumonia are the likely diagnoses in HIV-seropositive patients who have CD4+ $\mathrm{T}$ cell $>500 / \mu \mathrm{l}$. The diagnosis of chemical pneumonitis is clinical, based on circumstantial history and compatible radiographic findings, i.e. infiltrates in the superior-lower lobe or posterior-upper lobe in the supine state and in the basal segments of the lower lobe in the standing position preferably in right lung.

While initial radiographs may be normal, delayed radiographs are important in significant exposures. Longterm complications are bronchiectasis, bronchiolitis obliterans, and lung destruction. ${ }^{3}$
Prophylactic antibiotic and corticosteroids for lessening inflammation are advised in the treatment of chemical pneumonitis. Several multicentric clinical trials ${ }^{4}$ have concluded that antibiotic and corticosteroids are of no benefit in the treatment of chemical pneumonitis especially in initial stage. Negative pressure pulmonary edema is another condition that develops during regurgitation /aspiration of fluid, as a result of laryngeal spasm; however, the radiological feature of negative pressure pulmonary edema is bilateral symmetrical infiltration, which is in contrast to consolidation in the dependent part of the lung, commonly seen in chemical pneumonitis. $^{5}$

\section{CONCLUSION}

History of regurgitation of fluid in a patient with the recent consolidation in dependent part in CXR alerts for Chemical pneumonitis. Differential condition negative pressure pulmonary edema due to laryngeal spasm is distinguished from chemical pneumonitis by imaging.

\section{REFERENCES}

1. Mendelson CL. The aspiration of stomach content into the lungs during obstetric anaesthesia. Am J Obstet Gynecol. 1946; 52:191-205.

https://doi.org/10.1016/S0002-9378(16)39829-5

2. Bartlett JG. Aspiration pneumonia. Netter's Infectious Disease. Jong EC, Stevens DL (ed): Elsevier Inc, US; 2012; 1:153-156.

https://doi.org/10.1016/B978-1-4377-0126-5.00029-X

3. White CS and Templeton PA. Chemical pneumonitis. Radiol Clin North Am. 1992; 30:1231-1243.

4. Marik PE. Aspiration pneumonitis and Aspiration pneumonia. N Eng J Med. 2001; 344:655- 671.

https://doi.org/10.1056/NEJM200103013440908

5. Mandell LA and Niederman MS. Aspiration pneumonia. N Engl J Med. 2019; 380:651-663.

https://doi.org/10.1056/NEJMra1714562

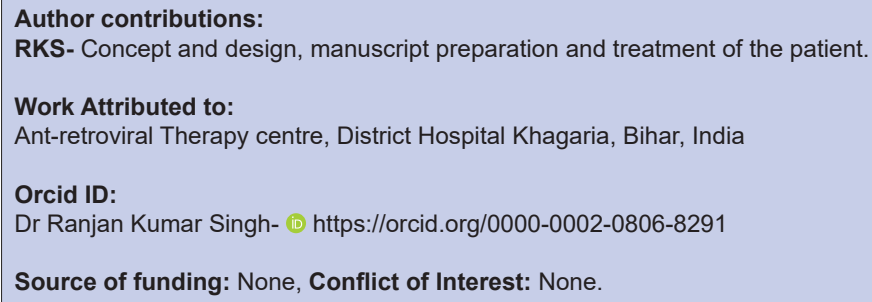

